\title{
Treatment of psoriasis and psoriatic arthritis during pregnancy and breastfeeding*
}

\author{
Patricia Shu Kurizky ${ }^{1,2}$ \\ Lucas Souza Carmo Nogueira ${ }^{4}$
}

\author{
Clarissa de Castro Ferreira ${ }^{3}$ \\ Licia Maria Henrique da Mota ${ }^{2}$
}

DOI: http:/ / dx.doi.org/10.1590/abd1806-4841.20153113

\begin{abstract}
A bstract: Psoriasis is a chronic inflammatory disease that affects primarily the skin and joints, with a worldwide incidence of 2-3\%. Fifty percent of patients are women, most still diagnosed during childbearing years. Currently, the estimate is that up to 107 thousand deliveries are performed annually in women with psoriasis, a percentage of them in women with moderate to severe disease. Fetal risks in pregnant women with psoriasis derive both from maternal disease and the medications used to control the illness. The purpose of this review is to study the effect of the main drugs used in the treatment of psoriasis and psoriatic arthritis during pregnancy and lactation, with particular focus on disease-modifying anti-rheumatic biological drugs, biological therapies, immunobiologics or biologics.
\end{abstract}

Keywords: Arthritis, psoriatic; Lactation; Pregnancy; Psoriasis

\section{INTRODUCTION}

Pregnancy planning in women with inflammatory diseases requires the adjustment of medications that are both able to maintain the disease stable and are also compatible with embryonic and fetal development. Withdrawal of all drugs before conception can lead to worsening of symptoms, which are as detrimental to the pregnancy prognosis as the continuation of substances able to harm the child's development. ${ }^{1}$

Psoriasis is a chronic disease with a worldwide prevalence of approximately $2-3 \%$, representing close to $5 \%$ of all cutaneous diseases..$^{2,3}$ Most studies did not observe differences between genders, so almost $50 \%$ of patients are women, many of childbearing age, since the average age of diagnosis is 28 years and nearly $75 \%$ of cases occur before the age of $40{ }^{2,4}$

The purpose of this article is to review the impact of drugs used in the treatment of psoriasis and psoriatic arthritis during pregnancy and lactation.

\section{CORRELATION BETWEEN PSORIASIS AND PREGNANCY}

The estimate is that 65 to 107 thousand deliveries occur annually in women with psoriasis, of which 9 to 15,000 have moderate to severe disease. 5 .6 Pregnancy may influence the severity of psoriasis. Approx- imately $55 \%$ of patients improve during pregnancy, $21 \%$ remain stable and $23 \%$ evolve with worsening of clinical manifestations., ${ }^{7,8}$ Moreover, a worsening of symptoms in the postpartum period is observed in about $40-90 \%$ of patients. Psoriatic arthritis occurs in $10-30 \%$ of patients with psoriasis. Pregnancy may act as a triggering factor for the articular disease and 30$40 \%$ of women relate the onset of psoriatic arthritis to the postpartum period. ${ }^{2}$

Risks to the fetus are dependent on the maternal disease activity and the medications used to treat it.

The uncontrolled inflammation and excess of cytokines inherent to the process of psoriasis can influence the course of pregnancy, however, little is reported about this topic. ${ }^{9}$ Psoriasis autoimmune inflammation resultsfrom dysfunctional T-helper cells with concomitant amplification of proinflammatory cytokines, mainly TNF- $\alpha$, IL-1 and IL- $6 .{ }^{5}$ Cytokine excess causes endothelial dysfunction, resulting in systemic and placental vasculopathies through platelet aggregation, intermittent vasospasm and activation of the coagulation system. ${ }^{5,9}$ Placental vasculopathy has been linked to intrauterine growth retardation and low birth weight. ${ }^{10}$ The stress associated with chronic and 
recurrent diseases tends to impact mental health, increasing the risk of alcohol abuse, depression, weight gain and smoking. ${ }^{11}$ Psoriasis is also associated with high rates of comorbidities, such as diabetes mellitus, cardiovascular diseases, obesity and metabolic syndromethat may also lead to complications during pregnancy and increase the risk of malformations. ${ }^{5,12}$ Studies show that pregnant women with psoriasis frequently present overweight/obesity, depression and smoking habits in the first trimester and are also less compliant with the intake of vitamins and prenatal supplements. ${ }^{5,11}$

\section{ANTIPSORIATIC TREATMENTS DURING PREGNANCY}

Studies evaluating the effects of antipsoriatic drugs on fetuses are still limited. ${ }^{5,13}$ One reason for this stems from the selective bias against studies in pregnant women for ethical reasons. Usually, available information regarding the use of these medications during pregnancy originates from case-control or retrospective studies with women who inadvertently used them. ${ }^{5,12}$ However, without a control group of untreated pregnant patients, the risk of teratogenic effects cannot be properly estimated. ${ }^{12}$ Studies in animals may be useful to identify which drugs may be teratogenic, but it is not always possible to generalize these findings to human pregnancy. Eventually, uncertainty leads to unnecessary interruption of pregnancies or inadequate treatment of mother and fetus. ${ }^{12}$

It is also important to recognize the available information regarding fetal malformations, when considering and evaluating teratogenicity. ${ }^{12}$ About $2 \%$ of all pregnancies have major congenital defects detected prenatally or at birth. ${ }^{14}$ Furthermore, $3 \%$ of children will have a diagnosis of congenital malformation during the first year of life. ${ }^{12}$ These rates may be higher depending on maternal age, family and past medical histories. ${ }^{12}$

\section{Topical treatments}

Topical treatment, with the exception of some medications, is the first-line treatment of psoriasis in pregnant and lactating women. ., $, 13,15^{2}$

Emollients should be tried first, because of their lack of adverse effects, followed by low to medium potency corticosteroids. ${ }^{715}$ High potency corticosteroids must be used, when necessary, rather in the second and third trimesters since, though not consensus, some studies have shown an association of their use with low birth weight. ${ }^{15}$ Safety and absorption of topical corticosteroids are related to several factors, such as formulation vehicle, quantity applied, occlusion and application site. A practical approach is to advise the patient not to apply excessive amounts over large areas, or on those under occlusion, to avoid excessive absorption and possible risk of low birth weight. ${ }^{13}$
While not approved for psoriasis, tacrolimus has been used to treat it on intertriginous areas. ${ }^{15}$ There are no studies on the use of topical tacrolimus during pregnancy, although there are considerable data on its oral use. Systemically, it has been associated with prematurity and low birth weight, although most likely the topical exposure would have lower correlation with those. Although oral tacrolimus has a safety pattern similar to cyclosporine, there are fewer studies available. ${ }^{15}$ Usually, topical calcineurin inhibitors have lower absorption than topical corticosteroids. ${ }^{16}$ Repeated applications, usage on large areas, and chronic use, were not associated with systemic drug accumulation in most studies. Some reports on systemic absorption of topical tacrolimus are found in patients with orofacial Crohn's disease, erosive lichen planus, pyoderma gangrenosum and lamellar ichthyosis. However, adverse events related to systemic absorption were not observed in either of these cases. ${ }^{15}$

Treatment with topical salicylic acid is controversial. Data regarding the influence of this drug's topical application during pregnancy is limited, and although some authors advocate its use in restricted areas, ${ }^{12}$ others contraindicate it, arguing that the absorption can be substantial. ${ }^{15}$ Some cases of salicylism have been reported with the use of topical salicylic acid in concentrations ranging from 1 to $40 \%$. Clinical presentations include abdominal pain, vomiting, lethargy, hallucinations, confusion, hypoglycemia, deafness, tinnitus, tachypnea, irritability, metabolic acidosis, coma and death. ${ }^{15}$

Risks of other topical agents, such as anthralin and calcipotriol on human studies are not known and thus most authors contraindicate these treatments. ${ }^{7,15}$ Calcipotriol is a by-product of vitamin D3, often used in combination with topical corticosteroids in order to increase their effectiveness and minimize irritation. ${ }^{12}$ Nevertheless, studies evidenced its systemic absorption in humans after application on psoriasis plaques and the development of vitamin D-induced toxicity after treatment with calcipotriol tends to increase the risk of teratogenicity. ${ }^{12}$

Although the number of cases is limited, coal tar has been associated with spontaneous abortions and congenital disorders, and was considered teratogenic in animal studies. Hence, it is not recommended during pregnancy. ${ }^{7,15}$ The main topical treatments used in psoriasis and their effects in pregnancy are summarized in chart $1,12,15$ according to available data collected from bibliographical references analyzed in preparation for this review.

Mild psoriasis, in general, can be adequately treated with topical drugs but systemic treatments may be required in moderate to severe psoriasis. 


\section{UVB phototherapy}

UVB phototherapy is the second-line treatment. $5,7,15$ Although data is limited, so far it was not associated with increased risk of fetal abnormalities or prematurity. ${ }^{13,15}$ In cases with extensive lesions, this seems to be the safest therapy, however overheating during treatment should be avoided, especially during the first 28 days of gestation, due to the increased risk of neural tube defects. ${ }^{13,15}$

\section{Systemic drug therapy}

Third-line treatments of psoriasis in pregnant women include systemic medications such as corticosteroids and cyclosporine. ${ }^{15}$

\section{Systemic corti costeroids}

Systemic corticosteroids are not routinely used in the treatment of psoriasis, because even though they result in the rapid clearing of lesions, reactivation

CHART 1: Effects of the main topical medications used in psoriasis during pregnancy

\begin{tabular}{|c|c|c|c|}
\hline Medication & Adverse events in pregnancy & Adverse events in animals & Conclusion \\
\hline \multicolumn{4}{|l|}{ Topical } \\
\hline Anthralin & No available data & No available data & $\begin{array}{l}\text { Contraindicated due to the } \\
\text { lack of available data }\end{array}$ \\
\hline Calcipotriol & No available data & $\begin{array}{l}\text { Increased incidence of skeletal ab- } \\
\text { normalities, and incomplete pu- } \\
\text { bic bones ossification }\end{array}$ & $\begin{array}{l}\text { Contraindicated due to the } \\
\text { lack of available data }\end{array}$ \\
\hline Corticoids & $\begin{array}{l}\text { Intrauterine growth retardation } \\
\text { reported }\end{array}$ & $\begin{array}{l}\text { Fetal growth retardation } \\
\text { Omphalocele and umbilical hernia }\end{array}$ & $\begin{array}{l}\text { Safe, except when used in } \\
\text { large amounts and extensive } \\
\text { areas, when it can be associat- } \\
\text { ed with low birth weight }\end{array}$ \\
\hline Coaltar & $\begin{array}{l}\text { Trisomy 13, spontaneous mis- } \\
\text { carriages }\end{array}$ & $\begin{array}{l}\text { Fetal death, growth retardation, } \\
\text { cleft palate, teratogenic }\end{array}$ & $\begin{array}{l}\text { Contraindicated due to the } \\
\text { lack of available data }\end{array}$ \\
\hline \multirow[t]{3}{*}{ Salicylic acid } & $\begin{array}{l}\text { Oral use causes maternal and } \\
\text { fetal hemostasis disorders }\end{array}$ & $\begin{array}{l}\text { Stenosis of the ductus arterio- } \\
\text { suswith systemic treatment }\end{array}$ & Contraindicated \\
\hline & $\begin{array}{l}\text { Reversible stenosis of the ductus } \\
\text { arteriosus }\end{array}$ & & \\
\hline & Salicylism & & \\
\hline Tacrolimus & $\begin{array}{l}\text { Low birth weight, prematurity } \\
\text { and hyperkalemia with system- } \\
\text { ic use }\end{array}$ & $\begin{array}{l}\text { Malformations, fetal growth re- } \\
\text { tardation, fetal death with sys- } \\
\text { temic treatment }\end{array}$ & $\begin{array}{l}\text { Probably safe for topical use, } \\
\text { however without enough } \\
\text { data }\end{array}$ \\
\hline Tazarotene & Few data in humans & $\begin{array}{l}\text { Teratogenic effects and fetal death } \\
\text { with systemic use }\end{array}$ & Contraindicated \\
\hline
\end{tabular}

The safety of PUVA with systemic psoralens is poorly known; although mutagenic potential has been demonstrated in studies with rats, few cases of prematurity and fetal abnormalities have been reported in pregnant women., ${ }^{5,15}$ Thus, this treatment is not recommended as an option for first or second line during pregnancy. ${ }^{15}$

Chart $2^{12,15}$ describes the effects of different modalities of phototherapy during pregnancy, according to data collected from bibliographical references analyzed in preparation for this review. of symptoms is common, demandingprogressively higher doses of medication with consequent increase in the incidence of adverseevents. ${ }^{17}$ Withdrawal of systemic corticosteroids is also generally accompanied by immediate disease relapse or rebound, characterized by diffuse eruptive lesions, affecting the face and the dorsal area of the hands. ${ }^{17}$ In addition, their use may precipitate the development of erythrodermic or generalized pustular psoriasis. ${ }^{18}$ They are indicated in the treatment of persistent erythrodermia unresponsive to other therapies, which may be causing metabolic com- 
ChART 2: Phototherapy modalities and their effects during pregnancy

\begin{tabular}{|llll|}
\hline M edication & Adverse events in pregnancy & Adverse events in animals & Conclusion \\
\hline Phototherapy & \multicolumn{1}{l}{ No available data } & $\begin{array}{l}\text { Probably safe, however with- } \\
\text { out enough data }\end{array}$ \\
Systemic PUVA & $\begin{array}{l}\text { Increased risk of low birth } \\
\text { weight after phototherapy with } \\
\text { methoxsalen in the mother } \\
\text { Prematurity, fetal abnormalities }\end{array}$ & $\begin{array}{l}\text { Increased fetal death rates, } \\
\text { growth retardation, enlargement } \\
\text { of cerebral ventricles, skeletal ab- } \\
\text { normalities }\end{array}$ & Contraindicated \\
UVB & $\begin{array}{l}\text { Case report with living birth } \\
\text { without alterations }\end{array}$ & No available data & Apparently safe \\
\hline
\end{tabular}

plications and also to treat von Zumbusch's fulminant generalized pustular psoriasis when other drugs are ineffective or contraindicated. ${ }^{17,19}$

The use of systemic corticosteroids during pregnancy is associated with low birth weight and intrauterine growth retardation..$^{15}$ The association between corticosteroid exposure in the first trimester and significant increase in orofacial clefts is controversial. After the placenta is developed, all steroids are inactivated by placental 11- $\beta$-hydroxylase, thus granting relative protection to the fetus. ${ }^{1}$ The prolonged use of corticoids increases the risk of prematurity, intrauterine growth restriction and the frequency of maternal adverse events such as hypertension, diabetes mellitus and osteoporosis. ${ }^{1}$ However, they constitute one of the recommended treatments for impetigo herpetiformis, severe pustular psoriasis, which commonly occurs in the later stages of pregnancy, and may be used to treat psoriatic arthritis. ${ }^{1,15}$ In these cases, planning the postpartum replacement is vital to avoid the often-fatal cutaneous rebound of the disease.

\section{Cyclosporine A}

The use of cyclosporine A in transplanted pregnant women showed no increased risk to the fetus and may be an option in psoriasis. ${ }^{5,20}$ Its use was associated with low birth weight and prematurity in infants born to transplanted women. ${ }^{20}$ Little information is found on its influence in pregnant women with psoriasis, nonetheless, do to the lack of teratogenic effects, most authors recommend its use in patients with severe psoriasis. ${ }^{5,13,15,20}$

\section{Other systemic medications}

Other systemic drugs commonly used in psoriasis, such as methotrexate and acitretin, are contraindicated during pregnancy. ${ }^{21}$ Methotrexate is teratogenic and mutagenic. It should be discontinued at least 3 months before conception. ${ }^{15}$ For methotrexate doses higher than $10 \mathrm{mg} /$ week, studies show that the sensitive period for malformations is between 6-8 weeks after conception. ${ }^{1}$ Its use can lead to abortions, micrognathia, delayed development, craniostenosis, low set ears, abnormalities of the extremities and intrauterine growth retardation. ${ }^{13}$ Systemic retinoids are teratogenic and cause cardiac, craniofacial, thymic and central nervous system malformations. ${ }^{13,15}$

The main effects of systemic drugs used in psoriasis and psoriatic arthritis during pregnancy are shown in chart 3,1,12, 15, 20, 21 according to data collected from bibliographical references analyzed in preparation for this review.

\section{Immunobiological therapies}

The experience with biological drugs during pregnancy is still limited. ${ }^{13}$

Theoretically, it is suggested that TNF- $\alpha$ is important in embryonic and fetal development and its depletion in mice leads to an increase in fetal death and structural defects. ${ }^{22}$ All anti-TNF- $\alpha$ drugs are, at least to a certain extent, IgG1 or IgG1-like antibodiesthat bind to TNF- $\alpha$ molecules causing down-regulation of their inflammatory actions. Human placenta appears to be impermeable to almost all major classes of antibodies, except IgG, which consists of four subclasses (IgG1-IgG4). ${ }^{22}$ Most of IgG in the fetus is of maternal origin, with IgG1 being the more effectively transported class. ${ }^{1}$ Fetal levels are low up to the second trimester and increasemarkedly from the beginning of the third trimester, until the fetal levels are higher than the maternal onesat term. ${ }^{1}$ There is variability in the specific active transport of each medication. For example, certolizumab has no Fc portion thus its active FcRn-mediated transplacental transport is not expected. ${ }^{22}$

Studies published between 2010 and 2012 confirmed earlier data, that the use of infliximab and adalimumab during pregnancy does not increase the risk of congenital malformations. ${ }^{1,23}$ 
CHART 3: Systemic drugs used in psoriasis and psoriatic arthritis and their influence during pregnancy

\begin{tabular}{|c|c|c|c|}
\hline Medication & Adverse events in pregnancy & A dverse events in animals & Conclusion \\
\hline \multicolumn{4}{|l|}{ Systemic } \\
\hline Acitretin & $\begin{array}{l}\text { Classic retinoid embryopathy } \\
\text { (craniofacial, cardiac, thymi- } \\
\text { cand central nervous system } \\
\text { malformations) }\end{array}$ & $\begin{array}{l}\text { Increased frequency of craniofa- } \\
\text { cial, limb and other types of mal- } \\
\text { formations }\end{array}$ & $\begin{array}{l}\text { Contraindicated, high risk of } \\
\text { malformations }\end{array}$ \\
\hline Corticoids & $\begin{array}{l}\text { Likely association with intrau- } \\
\text { terine growth retardation and } \\
\text { low birth weight, increased risk } \\
\text { of orofacial clefts }\end{array}$ & $\begin{array}{l}\text { Fetal growth retardation, steno- } \\
\text { sis of ductus arteriosus, craniofa- } \\
\text { cial, cardiac, genital and skeletal } \\
\text { anomalies, abdominal wall de- } \\
\text { fects, neural tube and CNS de- } \\
\text { fects, behavioral disorders }\end{array}$ & $\begin{array}{l}\text { Minimal risk of orofacial } \\
\text { clefts; should be avoided dur- } \\
\text { ing the first trimester }\end{array}$ \\
\hline Cyclosporine & $\begin{array}{l}\text { Increased risk of prematurity } \\
\text { andintrauterine growth retar- } \\
\text { dation, impairment in T, B and } \\
\text { NK cells development in ex- } \\
\text { posed children from mothers } \\
\text { with compromised health }\end{array}$ & $\begin{array}{l}\text { Alterations of immunological } \\
\text { functions, fetal growth retardatio- } \\
\text { nand death }\end{array}$ & $\begin{array}{l}\text { Risk of malformations, pre- } \\
\text { maturity, intrauterine growth } \\
\text { retardationand impairment } \\
\text { in T cells development is low } \\
\text { and may be linked to the ma- } \\
\text { ternal subjacent disease. Use } \\
\text { indicated in patients with se- } \\
\text { vere cases. }\end{array}$ \\
\hline Methotrexate & $\begin{array}{l}\text { Dose-dependent CNS, cranio- } \\
\text { facial and limb growth abnor- } \\
\text { malities (when used between } 6 \\
\text { and } 8 \text { weeks of gestation) }\end{array}$ & $\begin{array}{l}\text { Increased fetal death, dose-de- } \\
\text { pendent malformations of limbs, } \\
\text { craniofacial area, eyes, neural } \\
\text { tube and others }\end{array}$ & $\begin{array}{l}\text { Contraindicated during hu- } \\
\text { man pregnancy, high risk }\end{array}$ \\
\hline Sulfasalazine & $\begin{array}{l}\text { Absence of congenital malfor- } \\
\text { mations }\end{array}$ & No available data & Safe \\
\hline Leflunomide & $\begin{array}{l}\text { Absence of congenital defects } \\
\text { or recognizable pattern of mal- } \\
\text { formations }\end{array}$ & Teratogenic & $\begin{array}{l}\text { Limited data contraindicate } \\
\text { its use, but there is apparent- } \\
\text { ly low risk of teratogenicity in } \\
\text { humans }\end{array}$ \\
\hline Azathioprine & Prematurity & $\begin{array}{l}\text { Absence of congenital defects or } \\
\text { low birth weight }\end{array}$ & Safe \\
\hline
\end{tabular}

Infliximab and adalimumab are complete antibodies containing an IgG1 Fc portion actively transported through the placenta, that reach high blood levels in newborns after exposure during the late second and third trimesters. ${ }^{1}$ Since the half-life of immunoglobulins is longer than several months in the newborn child, there is an increased risk of infection. BCG vaccination with the live attenuated form of $M$ ycobacterium bovis administered at 3 months resulted in fatal disseminated infection in a child of 4.5 months, whose mother had received infliximab for Crohn's disease during pregnancy. ${ }^{24}$ This case led to the recommendation that vaccines with live agents should be avoided during the first months of life in children exposed to anti-TNF- $\alpha$ medications during pregnancy. ${ }^{22}$
Several case reports did not detect maternal adverse events or fetal anomalies after the use of adalimumab during pregnancy. ${ }^{15,23}$ Larger series are available on the use of infliximab. The largest published study is a retrospective analysis of 96 pregnancies; the rates of adverse events were similar to those of the general population and a case of tetralogy of Fallot and another of intestinal malrotation were reported..$^{22}$ In a systematic review of the literature in 2011,Bogas\& Leandro identified reports of 156 pregnancies exposed to infliximab and 106 to adalimumab, $70 \%$ and $90 \%$ of whichrespectively had been exposed during the first trimester. ${ }^{25}$ Congenital malformations were identified in 8 pregnancies treated with infliximab and 8 with adalimumab. The abnormalities usually occurred in 
isolated cases..$^{25}$ Despite favorable results, the routine use of these drugs in pregnancy is still questioned. ${ }^{7}$

Etanercept and certolizumab differ from other TNF- $\alpha$ inhibitors: etanercept is a fusion protein containing IgG1 Fc portion that presents less transplacental transport than other monoclonal antibodies. Its concentration in the umbilical cord is about $4-7 \%$ of the concentration detected in the maternal blood. ${ }^{1}$ Certolizumab pegol is a humanized anti-TNF antibody Fab fragment with high affinity to TNF,conjugated with 2 polyethylene glycol molecules. Therefore, it lacks the IgG Fc portion and there seems to be minimal transplacental transport, resulting in an average concentration in the umbilical cord of $3.9 \%$ of the maternal concentration, while with infliximab this rate is $160 \%{ }^{1}$

A study from the U.S. Organization of Teratology Information Specialist (OTIS) Research Group was performed with 17 pregnant women exposed to etanercept that resulted in live births, including twins. One of the twins had stomach malrotation, one child had unilateral inguinal hernia and another presented congenital hypothyroidism, however the mother had Hashimoto's thyroiditis. The authors concluded that there was no consistent pattern of abnormalities. ${ }^{26}$

Most case reports on etanercept conclude that there are no malformation or prematurity patterns. The only exception was one case with vertebral anomalies, anal atresia, cardiac disorders, tracheoesophageal fistula, esophageal atresia, kidney malformation and limb anomalies (formerly known as VATER syndrome) reported in $2006 .{ }^{27}$ This report was important, because based on animal models, there was a plausible connection between TNF- $\alpha$ inhibition and this syndrome. Subsequent revisions of cases submitted to the FDA by the same author, led to additional concerns about malformations in newborns whose mothers were treated with etanercept or infliximab. A nalysis of these cases showed that the alterations did not match VATER syndrome, rendering this case isolated and difficult to be interpreted as secondary to the use of that medication. ${ }^{15}$

Certolizumab is a Fab (antibody fragment that binds to the antigen fragment) without the Fc portion, directed against TNF- $\alpha$. Although not approved for psoriasis by the FDA, it has shown similar results to other TNF- $\alpha$ inhibitors in phase II studies in this disease. ${ }^{28}$ Since IgG is the only antibody that can be transferred from mother to fetus through the placenta barrier through a specific Fc portion receptor, this medication would result in lower fetal exposure. Although preliminary data seems positive, potential risks are still unknown. ${ }^{15}$

The OTIS group is conducting a cohort study with women, in the U.S. and Canada, which were exposed to immunomodulatory agents (including etanercept, adalimumab and certolizumab), comparing them to women with the same autoimmune diseases without exposure to biologic drugs and also to a healthy control group. Preliminary data analysis did not identified, until now, any pattern of defects and none of the patients met the criteria for association with VACTER. ${ }^{22}$

The British Registry documented 130 pregnancies in 118 women, classifying them into 3 groups: 1) women exposed to anti-TNF- $\alpha$ drugs at conception; 2) women exposed to anti-TNF- $\alpha$ drugsin the past; 3) control group. The rate of miscarriage was higher in group 1 compared to group 2 (24\% and $17 \%$, respectively). ${ }^{29}$

Based on the theory of low transplacental transport of these molecules in the first trimester, many experts advise discontinuation of treatment at conception or when pregnancy is confirmed. ${ }^{1,7}$ However, for those patients whosesymptoms tend to worsen during pregnancy or whose treatment discontinuation is not advisable, some authors advocate the maintenance of treatment during gestation. ${ }^{13,22}$ Nevertheless, given the increased placental transfer demonstrated during late pregnancy (at least for infliximab, etanercept and adalimumab) and suggestions of impaired immunity, many favorthe discontinuation of treatment in the third trimester. ${ }^{1,22}$

Ustekinumab is a monoclonal antibody that binds to the $\mathrm{p} 40$ subunit, common to IL-12 and IL-23, thus inhibiting the action of these cytokines. ${ }^{30}$ M ost of the available studies on ustekinumab were performed only in animals, so that most of the authors do not recommended its use during pregnancy. ${ }^{15} \mathrm{Although}$ there are few reports published in the literature up to June 2010, 42 unpublished cases of drug exposure during pregnancy were identified. ${ }^{31}$ In all pregnant women, the drug was discontinued in order to limit fetal exposure, since the transport of ustekinumab, a large IgG molecule, is modest until the late second and early third trimesters. Ten of these pregnancies resulted in live birthswithout abnormalities or adverse events, six resulted in spontaneous miscarriages, eight were electively discontinued, 2 were born alive, but with abnormalities and of the last 16 there was no information available. ${ }^{31}$ Andrulonis et al reported the case of a patient with erythrodermic psoriasis and psoriatic arthritis, which used the drug in the first six weeks of pregnancy and later in the $26^{\text {th }}$ and $37^{\text {th }}$ weeks, with improvement of the cutaneous and articular symptoms. The delivery was uneventful. Even so, breastfeeding was contraindicated due to evidence of drug passage through breast milk. ${ }^{30}$

Chart 4 details the main effects reported on immunobiological drugs during pregnancy.1, 9, 12, 15, 22, 26, 30, 31 


\section{CONSIDERATIONS ON PSORIATIC ARTHRITIS}

Cases of psoriatic arthritis associated with pregnancy are rare. As a rule, drugs and dosages are reduced. ${ }^{32}$ Among the modifying antirheumatic drugs, sulfasalazine and cyclosporine are favored..$^{32}$ One study with 74 pregnant women exposed to sulfasalazine did not demonstrate increase in congenital malformations, confirming previous studies., ${ }^{1,33}$
Methotrexate and cyclophosphamide inhibit cell division and are teratogenic to animals and humans, so, they are strictly contraindicated..$^{32,34}$

Psoriatic arthritis can be treated with steroids during pregnancy, especially prednisolone or prednisone. ${ }^{32}$

Leflunomide and azathioprine are occasionally used to treat psoriatic arthritis, with potential use in selected cases.

ChART 4: Biological drugs used in psoriasis and psoriatic arthritis and their influence during pregnancy

\begin{tabular}{|c|c|c|c|}
\hline Medication & Adverse events in pregnancy & Adverse events in animals & Conclusion \\
\hline \multicolumn{4}{|l|}{ Biological } \\
\hline Adalimumab & $\begin{array}{l}\text { Isolated cases of trisomy 18, } \\
\text { megacolon, ventricular sep- } \\
\text { tal defects, hemangioma, } \\
\text { Wolfe-Parkinson-White syn- } \\
\text { drome, neurofibromatosis, } \\
\text { VACTER syndrome, non-de- } \\
\text { scended testicle, microcephaly, } \\
\text { congenital hip dysplasia, hy- } \\
\text { dronephrosis. }\end{array}$ & Fetal death and structural defects & $\begin{array}{l}\text { Limited data available, if ad- } \\
\text { ministration is justified by the } \\
\text { severity of maternal illness, } \\
\text { discontinue it until 30th week }\end{array}$ \\
\hline Alefacept & No available data & No available data & $\begin{array}{l}\text { Contraindicated due to the } \\
\text { lack of available data }\end{array}$ \\
\hline Etanercept & $\begin{array}{l}\text { Isolated cases of VATER syn- } \\
\text { drome and trisomy } 18 \text { and } 21 \text {, } \\
\text { pyloric stenosis, hip dysplasia, } \\
\text { heart hypoplasia, inguinal her- } \\
\text { nia, congenital megacolon, ven- } \\
\text { tricular septal defects, trans- } \\
\text { verse stomach, hypospadias, } \\
\text { congenital hypothyroidism }\end{array}$ & Fetal death and structural defects & $\begin{array}{l}\text { Limited data available, if ad- } \\
\text { ministration is justified by the } \\
\text { severity of maternal illness, } \\
\text { discontinue it until 30th week }\end{array}$ \\
\hline Infliximab & $\begin{array}{l}\text { Isolated cases of congenital mal- } \\
\text { formations (tetralogy of Fallot, } \\
\text { intestinal malrotation, ventricu- } \\
\text { lar septal defects, anencephaly, } \\
\text { polydactyly, kidney agenesis), } \\
\text { intracerebral and intrapulmo- } \\
\text { nary bleeding, respiratory fail- } \\
\text { ure, developmental delay, death } \\
\text { from unknown causes } \\
\text { Disseminated fatal infection af- } \\
\text { ter BCG vaccination }\end{array}$ & Fetal death and structural defects & $\begin{array}{l}\text { Limited data available, if ad- } \\
\text { ministration is justified by the } \\
\text { severity of maternal illness, } \\
\text { discontinue it until 30th week }\end{array}$ \\
\hline Ustekinumab & Miscarriages & $\begin{array}{l}\text { Absence of adverse events re- } \\
\text { garding mortality, mental, mor- } \\
\text { phological and immunological } \\
\text { development } \\
\text { One study demonstrated viriliz- } \\
\text { ing effect in female monkeys }\end{array}$ & $\begin{array}{l}\text { Contraindicated due to limit- } \\
\text { ed available data }\end{array}$ \\
\hline Certolizumab & $\begin{array}{l}\text { Absence of congenital malfor- } \\
\text { mations }\end{array}$ & No available data & $\begin{array}{l}\text { Not yet approved for use in } \\
\text { psoriasis }\end{array}$ \\
\hline
\end{tabular}


Leflunomide is a pyrimidine synthesis inhibitor, which is teratogenic in rats, rabbits, and mice, and thus contraindicated during human pregnancy. Studies comparing the pregnancy of 64 patients with rheumatoid arthritis exposed to leflunomide in the first trimester and 108 unexposed subjects did not demonstrate increase in birth defects or recognizable patterns of malformation. ${ }^{1}$ This result was confirmed by a second study with 45 pregnancies exposed to leflunomide 2 years prior even to the first trimester. ${ }^{34}$ These data indicate that leflunomide is not a powerful human teratogen, although due to the limited number of pregnancies evaluated, the use of contraceptives is still recommended during its use and washout indicated in cases of unplanned pregnancies. ${ }^{1,34}$

Azathioprine can lead to premature births, although it was not associated to birth defects or low birth weight, confirming the possibility of its use in pregnancy when indicated. ${ }^{1}$

\section{ANTIPSORIATIC TREATMENTS DURING LACTATION}

Regarding lactating women, there is a lack of information about medication safety during the breastfeeding period. The first line of treatment for breastfeeding mothers is limited to emollients and low to medium potency corticosteroids. ${ }^{7}$ There are no known risks associated with emollients. Studies on topical steroids during lactation are negligible, however these drugs should be considered before systemic ones (for small areas) when psoriasis treatment is necessary. ${ }^{15}$ Creams should be applied after breastfeeding and removed before the next session. ${ }^{7}$

No studies were found about UVB therapy in lactating women, but it seems to be safe and is indicated as a second-line treatment in these patients. ${ }^{7,15}$

Systemic corticosteroids may be used if necessary, since minimal concentrations are detected in breast milk. Because cortisol half-life varies between 2.5 and 3.5 hours, the authors recommend an interval of 4 hours between the intake of systemic corticosteroids and breastfeeding. ${ }^{15}$

Systemic medication levels can be measured in breast milk. The significance of these dosages is uncertain due to limited reports. Thus, methotrexate, acitretin, cyclosporine, and psoralen (PUVA) are contraindicated during breastfeeding. 15,21

Data on the use of biological drugs are still sparse. The absorption of maternal antibodies through breast milk in humans is limited, with IgA as the predominant immunoglobulin isotype providing immunity to infants' intestinal mucosa. ${ }^{35}$ Small amounts of IgG and other larger immunoglobulins cross the breast acini and thus cannot be found, in significant quantities, in the blood of infants. For this reason, the passage of anti-TNF drugs through breast milk is expected to be min- imal. There are few data from experimental (animal) or clinical studiesto support this information.

Regarding etanercept, the case of a woman with ankylosing spondylitis, who used the medication throughout pregnancy and lactation, was described. Drug concentration was determined in maternal blood, cord blood, breast milk and the infant's blood. Maternal-to-cord blood concentration ratio was 14:1, which shows low transplacental passage. Concentration in the breast milk was $5 \mathrm{ng} / \mathrm{ml}$ - a very low value, and etanercept was not detected in the infant's blood. ${ }^{36}$ It is believed that, because it is a large protein, the oral absorption of etanercept is minimal or null. ${ }^{37}$

In regard to infliximab, the case of a woman with inflammatory bowel disease, who used high doses of infliximab (10mg/kg 4 in 4 weeks) during pregnancy and lactation due to a lack of response to conventional doses, has been described. Breast milk was collected and analyzed: infliximab was not detected. The pregnancy went uneventfully and the child did not show any physical or developmental abnormalities. ${ }^{37}$

There are no consistent data on the passage of other biological drugs through breast milk.

The use of biological drugs during lactation is controversial. Bae et al claim that, despite limited data and according to reported evidence, the levels of medications in the breast milk of lactating women treated with etanercept or infliximab have been described as smaller than those used in the treatment, so it appears that no significant absorption occurs in infants. ${ }^{15}$ Nevertheless, also in view of limited data, Wheatherhead et al contraindicate its use. ${ }^{7}$

\section{CONCLUSIONS}

Topical treatments are the first line treatment of psoriasis in pregnant and lactating women. In moderate to severe cases, UVB phototherapy is the second line of treatment and the third line features systemic drugs.

Information found in the literature on the use of biological drugs during pregnancy and lactation is scarce, and as directed by the prescribing information packets, the use of these drugs should be avoided during pre-conception, pregnancy and lactation periods.

However, with respect to anti-TNF- $\alpha$, based on the evidence described and inferring on the currently existing guidelines on its use in patients with inflammatory bowel disease, it would be possible to adopt the following recommendations: ${ }^{38}$

Pre-conception exposure: since anti-TNF- $\alpha$ hypothetically does not cross the placental barrier in the first trimester, it would be possible to allow its use until the moment of conception.

Exposure during pregnancy: anti-TNF- $\alpha$ drugs should be suspended during pregnancy. In case of very severe disease activity and after discussing it with the 
patient, it is possible to contemplate the eventual prescription or reintroduction of the drug, preferably, if feasible, with reduced doses, larger periods between applications, and treatment suspension between 8 to 10 weeks before the expected date of delivery.
Exposure during lactation: anti-TNF- $\alpha$ drugs should be avoided during lactation. However, in case of intense disease activity, prescribing such drugs would be possible if the benefit to the mother outweighed the risk to the child.

\section{REFERENCE}

1. Ostensen M, Forger F. How safe are anti-rheumatic drugs during pregnancy? Curr Opin Pharmacol. 2013;13:470-5

2. Tauscher AE, Fleischer AB Jr, Phelps KC, Feldman SR. Psoriasis and pregnancy. J Cutan Med Surg. 2002;6:561-70.

3. National Psoriasis Foundation. About psoriasis: statistics. [cited 2013 Nov 10] Available from: http://www. psoarisis.org/learn_statistics.

4. Carneiro JN. Artrite psoriásica em pacientes com psoríase: avaliação de características clínicas e epidemiológicas em um grupo de 133 pacientes brasileiros. [dissertação]. Brasília (DF): Universidade de Brasília; 2011. p.96.

5. Lam J, Polifka JE, Dohil MA. Safety of dermatologic drugs used in pregnant patients with psoriasis and other inflammatory skin diseases. J Am Acad Dermatol. 2008;59:295-315.

6. Landau JL, Moody MN, Kazakevich N, Goldberg LH. Psoriasis and the pregnant woman: what are the key considerations? Skin Therapy Lett. 2011;16:1-3

7. Horn EJ, Chambers CD, Menter A, Kimball AB; International Psoriasis Council. Pregnancy outcomes in psoriasis: why do we know so little? J Am Acad Dermatol. 2009;61:e5-8.

8. Weatherhead S, Robson SC, Reynolds NJ. Management of psoriasis in pregnancy. BMJ. 2007;334:1218-20.

9. Griffiths CE. Management of psoriasis in pregnancy: time to deliver? $\mathrm{Br} J$ Dermatol. 2010;163:235.

10. Yang YW, Chen CS, Chen YH, Lin HC. Psoriasis and pregnancy outcomes: a nationwide population-based study. J Am Acad Dermatol. 2011;64:71-7.

11. Guven MA, Coskun A, Ertas IE, Aral M, Zencirci B, Oksuz H. Association of maternal serum CRP, IL-6, TNF-a, homocysteine, folic acid and vitamin B12 levels with the severity of preeclampsia and fetal birth weight. Hypertens Pregnancy. 2009;28:190-200.

12. Bandoli G, Johnson DL, Jones KL, Lopez Jiminez J, Salas E, Mirrasoul N, et al. Potentially modifiable risk factors for adverse pregnancy outcomes in women with psoriasis. Br J Dermatol. 2010;163:334-9.

13. Tyler KH, Zirwas MJ. Pregnancy and dermatologic therapy. J Am Acad Dermatol. 2013;68:663-71.

14. Richmond S, Atkins J. A population-based study of the prenatal diagnosis of congenital malformation over 16 years. BJOG. 2005;112:1349-57.

15. Bae YS, Van Voorhees AS, Hsu S, Korman NJ, Lebwohl MG, Young M, et al. Review of treatment options for psoriasis in pregnant or lactating women: From the medical Board of National Psoriasis Foundation. J Am Acad Dermatol. 2012;67:459-77.

16. Pariser D. Topical corticosteroids and topical calcineurin inhibitors in the treatment of atopic dermatitis: focus onpercutaneous absorption. Am J Ther. 2009;16:264-73.

17. Griffiths CEM, Camp R, Barker JNWN. Psoriasis. In: Burns T BS, Cox N, Griffiths C, editors. Rook's Textbook of Dermatology. Italy: Blackwell Science; 2004. p.35.46-35.47.

18. Baker H. Corticosteroids and pustular psoriasis. Br J Dermatol. 1976;94:83-8.

19. Ryan TJ, Baker H. Generalized pustular psoriasis. A clinical and epidemiological study of 104 cases. Br J Dermatol. 1968;80:771-93.

20. Rosmarin DM, Lebwohl M, Elewski BE, Gottlieb AB; National Psoriasis Foundation. Cyclosporine and psoriasis: 2008 National Psoriasis Foundation Consensus Conference. J Am Acad Dermatol. 2010;62:838-53.

21. Hale EK, Pomeranz MK. Dermatologic agents during pregnancy and lactation: an update and clinical review. Int J Dermatol. 2002;41:197-203.

22. Chambers CD, Johnson DL. Emerging data on the use of anti-tumor necrosis factor-alpha medications in pregnancy. Birth Defects Res A Clin Mol Teratol. 2012:94:607-11.

23. Dessinioti C, Stefanaki I, Stratigos AJ, Kostaki M, Katsambas A, Antoniou C. Pregnancy during adalimumab use for psoriasis. J Eur Acad Dermatol Venereol. 2011;25:738-9.
24. Cheent K, Nolan J, Shariq S, Kiho L, Pal A, Arnold J. Case report: fatal case of disseminated BCG infection in an infant born to a mother taking infliximab for Crohn `s disease. J Crohns Colitis. 2010;4:603-5.

25. Bogas M, Leandro M. Biologic therapy and pregnancy. Acta Reumatol Port. 2011;36:219-32.

26. Chambers C, Jonhson D, Jones K. Pregnancy outcomes in women exposed to etanercept: the OTIS autoimune diseases in pregnancy project. J Am Acad Dermatol. 2007;56:AB10.

27. Carter JD, Valeriano J, Vasey FB. Tumor necrosis factor-alpha inhibition and VATER association: a causal relationship J Rheumatol. J Rheumatol. 2006;33:1014-7.

28. Ortonne JP, Reich K, Sterry W, Terpstra I. Safety and efficacy (PASI 90 and global evaluation) of subcutaneous certolizumab pegol in patients with moderate to severe chronic plaque psoriasis: Results from a double-blind, placebo-controlled trial. J Am Acad Dermatol. 2008;58:AB4.

29. Verstappen SM, King Y, Watson KD, Symmons DP, Hyrich KL; BSRBR Control Centre Consortium, BSR Biologics Register. Anti-TNF therapies and pregnancy: outcome of 130 pregnancies in the British Society for Rheumatology Biologics Register. Ann Rheum Dis. 2011;70:823-6.

30. Andrulonis R, Ferris LK. Treatment of severe psoriasis with ustekinumab during pregnancy. J Drugs Dermatol. 2012;11:1240.

31. Fotiadou C, Lazaridou E, Sotiriou E, loannides D. Spontaneous abortion during ustekinumab therapy. J Dermatol Case Rep. 2012;6:105-7.

32. Matuszewska A, Misterska-Skóra M, Wiland P. Active psoriatic arthritis during pregnancy: challenges and limitations of pharmacotherapy. Ann Acad Med Stetin. 2010;56:45-7

33. Viktil KK, Engeland A, Furu K. Outcomes after anti-rheumatic drug use before and during pregnancy: a cohort study among 150,000 pregnant women and expectant fathers. Scand J Rheumatol. 2012;41:196-201.

34. Cassina M, Johnson DL, Robinson LK, Braddock SR, Xu R, Jimenez JL, et al. Pregnancy outcome in women exposed to leflunomide before or during pregnancy. Arthritis Rheum. 2012;64:2085-94.

35. Kane SV, Acquah LA. Placental transport of immunoglobulins: a clinical review for gastroenterologists who prescribe therapeutic monoclonal antibodies to women during conception and pregnancy. Am J Gastroenterol. 2009;104:228-33.

36. Berthelsen BG, Fjeldsøe-Nielsen H, Nielsen CT, Hellmuth E. Etanercept concentrations in maternal serum, umbilical cord serum, breast milk and child serum during breastfeeding. Rheumatology (Oxford). 2010;49:2225-7.

37. Stengel JZ, Arnold $\mathrm{H}$. Is infliximab safe to use during breastfeeding? World J Gastroenterol. 2008;14:3085-7.

38. Habal FM, Huang V. Review article: a decision-making algorithm for the management of pregnancy in the inflammatory bowel disease patient. Aliment Pharmacol Ther. 2012;35:501-15.

\begin{tabular}{l}
\hline M AILING ADDRESS: \\
Patricia Shu Kurizky \\
A mbulatório de D ermatologia do H ospital U niversitário de \\
Brasília \\
SGA N, Q uadra 604, A venida L2 N orte, s/n - A sa N orte, \\
70840-901 - Brasília - D F \\
Brazil \\
E-mail: patyshu79@gmail.com
\end{tabular}

Patricia Shu Kuriz

A mbulatório de D ermatologia do H ospital U niversitário de Brasília

SGA N, Quadra 604, A venida L2 N orte, s/n - A sa N orte, Brazi

E-mail.patyshu79@gmail.com

How to cite this article: Kurizky PS, Ferreira CC, Nogueira LSC, Mota LMH. Treatment of psoriasis and psoriatic arthritis during pregnancy and breastfeeding. An Bras Dermatol. 2015; 90(3):367-75. 